\title{
Reply to Nina Hood's 'Manifestations of Autonomy and Control in a Devolved Schooling System: The Case of New Zealand'
}

\author{
Irene Bucelli (London School of Economics and Political Science)
}

In 'Manifestations of Autonomy and Control in a Devolved Schooling System: The Case of New Zealand', Nina Hood explores tensions and contradictions that have characterised the education system in New Zealand showing how these affect teachers' control and autonomy. Much has been written in relation to the 'deprofessionalisation' that characterises the global educational reform movement 'GERM' (Sahlberg, 2016); and the contradictions that underlie some of these reforms have been explored in different contexts (Trowler, 2003). What this article adds is not just closer look at how teachers navigate the pressures imposed by these contradictions in the context of New Zealand; it most importantly, problematises the requirements of expertise and professional capital that are necessary for teachers to operate at the level of autonomy and control that the system envisages. The three examples chosen to showcase this the devolution of the school system, the introduction of a content-free curriculum, and the implementation of National Standards together with the use of overall teacher judgments as primary measurement tool - are effective and function well also to show the range of diverse professional activities over which teachers exercise different levels of autonomy and control.

This is a welcome contribution as it is common to discuss losses of autonomy and control experienced by the teaching profession following 'GERM' reforms but the very notion of what this autonomy and control entails and requires is much less clearly explored in the literature. Autonomy means having both the competence and the opportunity to exercise an active role in relation to educational ends and their implementation (Bucelli, 2017). In this sense, the article shows the space occupied by teachers in the three areas and points to the tensions and the potential contraction of these spaces in light of GERM principles. But it also emphasises the need of putting in place the conditions to develop the relevant forms of knowledge and expertise necessary to engage actively in these activities and effectively exercise an autonomous role. Understanding education as a public good allows a key participatory role for teachers. In order for teachers to effectively act as interlocutors and partners in the construction of the public good, the conditions for autonomy and control need to be developed and exercised: this means fostering competence and design opportunities within institutional structures that allow for forms of partnership, dialogue and professional progression. Without fulfilling these conditions professional autonomy is hollowed out and open to challenges to its role within the education system. This is all the more important because underpinning the impetus behind 'GERM' reforms - for instance in the USA with 'A Nation at Risk' and in England with the 1988 Education Reform Act - has been the idea that alternatives were necessary in face of a 'crisis' that required structural changes to drive up academic standards and introduce new accountability tools. Le Grand (2007) has described associated reforms, which moved the system towards establishing a quasi-market in education through choice and competition, as a move away from a 'trust' model of service provision - a model in which qualified professionals are trusted to allocate resources and deliver services. This shift, and the associated demand for new accountability measures, effectively questioned the capacity of teaching professionals to fulfil their role with the type of autonomy just described.

In light of this, a finer grain analysis of accountability would have been welcome. The literature has offered different frameworks to understand different types of accountability in school-based education (Mattei, 2012; West, Mattei, \& Roberts, 2011). Hierarchical and market accountability - which seem to be considered by the article in conjunction as 'external accountability' measures - do seem inextricably linked in many contexts, with both forms of accountability stressing the same indicators, which can lead to sanctions under hierarchical accountability mechanisms but also drive competition and inform consumers in their choices under market accountability. These need also to be distinguished, as less marketised regimes may retain hierarchical mechanisms with consequences for standardisation which would keep affecting professional autonomy in the sense discussed by the article. A finer-grained analysis, as that developed by West et al. (2011) which distinguishes between professional, hierarchical, market, contract, legal, network and participative types of accountability, has the advantage of being able to ask questions around the forms of accountability that would be relevant for the 'equity approach', as it is defined in the article. 
Here the case of New Zealand outlined by Hood (2019) is particularly interesting because of how in face of the tensions between the two discussed approaches, the system has not adopted stringent hierarchical and market accountability measures and the introduction of National Standards has not coincided with an emphasis on highstakes assessment. This is relevant because research (e.g., West et al., 2011) has shown how the different strength and likelihood of sanctions associated to these different types of accountability regimes has a major effect on the behaviours and strategies adopted by schools and teachers (while also substantially affecting student's approach to learning). In contexts which do make use of market and hierarchical accountability regimes, schools follow their demands, at the expense of softer forms of professional, participative and network accountability, which are characterised by a low likelihood of severe sanctions. In the context of New Zealand, there is room for these forms of accountability to retain weight and be utilised to support collaborative practices and the development of professional capital. Here a finer grain analysis could have led the article to move beyond diagnosing the tensions and the weaknesses it helpfully identifies, and towards an exploration of the opportunities to support an 'equity approach' which would in turn be more fleshed out.

Two further related issues, which the focus on the New Zealand system brings to the fore, could have also been explored in more depth. Hood (2019) shows how the introduction of National Standards led to consequences such as loss of morale and narrowing practices and the article suggests that this is due to the top-down accountability measures the reform introduces. However, these phenomena are often discussed in the literature in relation to high-stakes regimes, while New Zealand's remains generally low-stakes. This makes the case more complex than the article acknowledges. The article could have connected this analysis to that of the pressures that expertise and professional requirements exert on teachers, as they navigate an environment in which they are responsible for curriculum design and overall teacher judgments while also operating in a context characterised by tensions between two contrasting education approaches. This could have led to a more original discussion of how these dynamics can be explained in a low-stakes environment (questions which are connected to Hangartner (2019) in this collection). Moreover, the article briefly discusses changing relationships among teachers. Again, the literature on high-stakes regimes has long discussed this: relationships among teachers see competition undermining cooperation, affecting the collegiality that is integral to professionalisation, while relationships between teachers and headteachers and between teachers and students are also disrupted - particularly in contexts of performance-related pay. It is less clear why and how these relationships are altered in the New Zealand context, and investigating this would have been an important contribution. Both of these elements are often discussed in relation to how performativity contexts undermine autonomy and control through the loss of authenticity (Ball, 2003) and colonisation of teachers' subjectivity (Cribb and Gewirtz, 2007). This article could have introduced nuances in this debate through its problematisation of autonomy and control. This would have led to questions about the pressure of navigating a space in which opportunities for autonomy persist but are changing and introduce new professional needs, while the competence to respond to these needs requires to be supported, if negative consequences to teachers' experience is to be avoided and professional practice is to maintain its legitimacy.

\section{References}

Ball, S. J. (2003). The teacher's soul and the terrors of performativity. Journal of Education Policy, 18(2), $215-228$. https://doi.org/10.1080/0268093022000043065

Bucelli, I. (2017). The role of 'autonomy' in teaching expertise. Journal of Philosophy of Education, 51(3), 588-604. https://doi.org/10.1111/1467-9752.12252

Cribb, A., \& Gewirtz, S. (2007). Unpacking autonomy and control in education: Some conceptual and normative groundwork for a comparative analysis. European Educational Research Journal, 6(3), 203-213. https://doi.org/10.2304/eerj.2007.6.3.203

Hangartner, J. (2019). Control of teachers under conditions of low-stakes accountability. On Education. Journal for Research and Debate, 2(5). https://doi.org/10.17899/on_ed.2019.5.4

Hood, N. (2019). Manifestations of autonomy and control in a devolved schooling system: The case of New Zealand. On Education. Journal for Research and Debate, 2(5). https://doi.org/10.17899/on_ed.2019.5.6

Le Grand, J. (2007). The other invisible hand: Delivering public services through choice and competition. Princeton, NJ: Princeton University Press.

Mattei, P. (2012). Market accountability in schools: Policy reforms in England, Germany, France and Italy. Oxford Review of Education, 38(3), 247-266. https://doi.org/10.1080/03054985.2012.689694 
Sahlberg, P. (2016). The Global Educational Reform Movement and its impact on schooling. In K. Mundy, A. Green, B. Lingard, \& A. Verger (Eds.), The handbook of global education policy (pp. 128-144). https://doi.org/10.1002/9781118468005.ch7

Trowler, P. (2003). Education policy (2nd ed.). London: Routledge.

West, A., Mattei, P., \& Roberts, J. (2011). Accountability and sanctions in English schools. British Journal of Educational Studies, 59(1), 41-62. https://doi.org/10.1080/00071005.2010.529416

\section{Recommended Citation}

Bucelli, I. (2019). Reply to Nina Hood's 'Manifestations of Autonomy and Control in a Devolved Schooling System: The Case of New Zealand'. On Education. Journal for Research and Debate, 2(5). https://doi.org/10.17899/on_ed.2019.5.8

\section{About the Author}

Dr Irene Bucelli is a researcher at the Centre for Analysis of Social Exclusion at the London School of Economics and Political Science. She holds a PhD in Philosophy from King's College London and her post-doctoral work at the LSE has been in the field of social policy. She focuses on multidimensional inequalities, including educational inequalities. She has previously published on the topic of professional autonomy on the Journal of Philosophy of Education. 